(C) Entomologica Fennica. 15 February 2016

\title{
Starvation resistance of invasive lace bug Corythucha ciliata (Hemiptera: Tingidae) in China
}

\author{
Hai-Wei Wu, Xian-Chen Li \& Huan-Xiu Liu
}

\begin{abstract}
Wu, H.-W., Li, X.-C. \& Liu, H.-X. 2016: Starvation resistance of invasive lace bug Corythucha ciliata (Hemiptera: Tingidae) in China. - Entomol. Fennica 27: $8-14$.
\end{abstract}

Food shortage is a prevalent threat to insect survival and successful reproduction in natural settings. An insect species invading new areas may have a high capacity to survive and adapt to starvation. To test these hypotheses, we assessed the survival time of Corythucha ciliata (Say), in a laboratory under two starvation conditions: complete starvation (no food supplied) and gradual starvation (food provided once and not replenished). Under complete starvation, survival of $3^{\text {rd }}$ to $5^{\text {th }}$ instar nymphs tended to decline steadily, whereas under gradual starvation this process was delayed in the initial stage. The average survival times increased as the instar increased under both conditions $(14.0 \mathrm{~h}, 15.9 \mathrm{~h}$ and $24.4 \mathrm{~h}$ under complete starvation conditions; $27.8 \mathrm{~h}, 29.6 \mathrm{~h}$ and $33.6 \mathrm{~h}$ under gradual starvation conditions). The longest lived individual nymph survived for 49 hours. The results may partially explain the rapid global expansion of $C$. ciliata.

\section{H.-W. Wu, X.-C. Li \& H.-X. Liu, Shandong Academy of Forestry, No.42 Wenhua Dong Road, Jinan, Shandong Province 250014, China; Corresponding author's e-mail:haiweiw@126.com}

Received 27 March 2015, accepted 10 August 2015

\section{Introduction}

Food shortages negatively impact insect growth rates (Berrigan \& Charnov 1994, Bauerfeind et al. 2005), maximum body size (Blanckenhorn 1998; Boggs \& Freeman 2005) and reproductive output (Jiang \& Lin 1965, Lin et al. 2003, Karl et al. 2007, Kehl \& Fischer 2012) as well as other life history traits (Boggs \& Ross 1993, Braby \& Jones 1995, Bauerfeind et al. 2005, Daglish 2006, Ju et al. 2008, Zheng et al. 2011). Insects can suffer food shortages due to changes in food quality or availability, changes in food preferences, and food depletion. Insects have evolved several mechanisms to respond to starvation stress. These include delaying development until sufficient resources have been secured, undergoing accelerated metamorphosis, and eclosing as smaller adults when resources are scarce during the larval stage (Chen \& Gu 2006). The ability to address this stress is called starvation resistance.

Starvation resistance is of great interest to insect ecologists because of its close correlation with fitness in natural populations of many organisms and because it often co-varies with longevity (Stockhoff 1991, Johnson et al. 2001, Chen \& Gu 2006, Sheng et al. 2007, Pijpe et al. 2008, Zhang et al. 2012). Body size, body composition and metabolic rate strongly affect starvation resistance (Stockhoff 1991, Lavy et al. 1997, Robinson et al. 2000, Vermeulen et al. 2006).

The current study concerns starvation resis- 
tance in the sycamore lace bug Corythucha ciliata (Say) (Hemiptera: Tingidae), a recently recognised invasive pest in China (Ju et al. 2009). Corythucha ciliata is a native North American insect occurring east of the Rocky Mountains (Froeschner 1988). In Europe, it was first discovered in 1964 in Padova, Italy, and subsequently spread throughout Europe over the course of 20 years (Rabitsch 2008). Corythucha ciliata has also been introduced to Chile (Prado 1990), Korea (Chung et al. 1996), Japan (Tokihiro et al. 2003), Australia (Dominiak et al. 2008) and China (Ju et al.2009). In China, it has dispersed throughout eastern China, mid-China and southwestern China since it was first observed in 2006 in Wuhan, Hubei province (Li et al. 2007, Xiao et al. 2010, Liu et al. 2012, Ji et al. 2013, Wu et al. 2013). Corythucha ciliata has caused great damage in 12 other provinces (Shanghai, Zhejiang, Anhui, Jiangsu, Guizhou, Sichuan, Chongqing, Hunan, Hubei, Henan, Shandong and Beijing) in less than a decade (Ju et al. 2009).

The diffusion speed of $C$. ciliata has been very fast (Kukedi 2000, Mazzon \& Girolami 2000, Hoffmann 2003) due to both the phenology of the invasive pest itself and to environmental factors (Ju et al. 2009). Corythucha ciliata can survive, develop, and reproduce over a wide range of temperatures (Ju et al. 2011a). In addition, exposure to high temperatures ranging from 35 to $41^{\circ} \mathrm{C}$ for $2 \mathrm{~h}$ does not reduce the survival, longevity, or fecundity of $C$. ciliata adults, indicating that this species has great thermal tolerance (Ju et al. 2011b, 2013). Moreover, C. ciliata is extremely cold tolerant and can withstand temperatures as low as $-23{ }^{\circ} \mathrm{C}$ in nature (Halbert \& Meeker 1998). This insect also has extremely high fecundity: a female can lay 350 eggs in the wild (d'Aguilar et al. 1977). Collectively, these bioecological characteristics of $C$. ciliata may partially explain why it has rapidly spread on Platanus trees throughout the world.

The long-distance diffusion of $C$. ciliata populations likely occurs primarily by artificial propagation via host plants, vehicles, or other biological and non-biological carriers (Halbert \& Meeker 1998). During diffusion, the lace bug suffers food shortages or even the absence of food. We hypothesise that this species has a great capacity to adapt to starvation and that its starvation resistance plays an important role in its invasive process.

There may be a very complex mechanism for the adults to cope with starvation. For example, overwintering adults of $C$. ciliata can survive more than 150 days in the absence of any food (Arzone 1975; Kim \& Jeong 1999; Xiao et al. 2010). In the present study, we conducted laboratory analyses to assess the effects of starvation on newly emerged $3^{\text {rd }}$ to $5^{\text {th }}$ instar nymphs of $C$. ciliata. We restricted our study to $3^{\text {rd }}$ to $5^{\text {th }}$ instars, because it was too hard to get newly emerged nymphs $(<3 \mathrm{~h}$ old $)$ of all the instars at the same time. Even if using just those three nymphal instars, the study most likely aids understanding some basic rules on starvation resistance for the sycamore lace bug, especially the longest surviving time of those nymphs. We will investigate the starvation resistance of adults at different generations in future studies.

We answered the following questions. (1) What are the survival patterns of C. ciliata nymphs under complete starvation conditions (no food supplied) and gradual starvation conditions (food provided once and not replenished)? (2) How long can they live under the two conditions?

\section{Materials and methods}

\subsection{Insects}

A laboratory colony of $C$. ciliata was established in May 2015 from nymphs collected from London plane trees (Platanus acerifolia (Ait.) Willd.) in Jinan, China $\left(36.687^{\circ} \mathrm{N}, 117.070^{\circ} \mathrm{E}\right)$. The insects were reared on leaves of $P$. acerifolia in a mesh cage $(100 \times 60 \times 60 \mathrm{~cm})$. One branch with 5 -6 leaves was placed in the cage with the cut end of the branch placed in a water-filled bottle. Fresh branches from London plane trees and the water in the bottle were changed as needed to ensure food availability and to prevent desiccation. Each cage held approximately 200 individuals. The stock culture was maintained in the laboratory at $26 \pm 0.5^{\circ} \mathrm{C}$ with a relative humidity of $70 \pm 5 \%$ and a 14 h:10 h (L:D) photoperiod (see Ju et al. 2011c). Newly emerged $3^{\text {rd }}$ to $5^{\text {th }}$ instar nymphs $(<3 \mathrm{~h}$ old $)$ of the F2 generation were used in the following experiments. 


\subsection{Measurement of starvation resistance}

Newly emerged $3^{\text {rd }}$ to $5^{\text {th }}$ instar nymphs ( $<3$ h old $)$ from stock cultures were transferred to empty plastic insect-rearing boxes $(12 \times 9 \times 10 \mathrm{~cm})$ using a small brush, which were then placed in an intelligent artificial climate chamber (Model: RXZ-280C, Ningbo Jiangnan Instrument Co., Ltd.) at $26 \pm 0.5^{\circ} \mathrm{C}$ with a relative humidity of 80 $\pm 5 \%$ and a $14: 10 \mathrm{~L}: \mathrm{D}$ photoperiod. In complete starvation treatment, no food was provided during the tests. In gradual starvation treatment, a fresh leaf was placed in the rearing box before newly emerged $3^{\text {rd }}$ to $5^{\text {th }}$ instar nymphs were transferred to the box to supply food for nymphs in the initial stage of the experiment. The leaf was not replaced during the experiment, resulting in gradual starvation. Corythucha ciliata reared in the box containing a fresh leaf of $P$. acerifolia were used as a control; their leaf was changed as needed to ensure a steady food supply, and all other conditions were the same as above.

The numbers of dead nymphs and moulting nymphs were recorded every hour. A nymph was considered dead, if none of its appendages moved after all appendages were touched with a brush (Ju et al. 2013). Three replicates with at least 30 individuals of each instar per replicate were evaluated for each treatment. All rearings were performed simultaneously in the same single climate chamber with an interspersed spatial arrangement of the replicates of the different treatments (and control).

\subsection{Statistical analyses}

The survival patterns of the $C$. ciliata nymphs under complete starvation conditions and gradual starvation conditions were assessed by curves that described age-specific survivorship over hours. The results are presented as the mean values $\pm \mathrm{SE}$ ( $\mathrm{n}=3$ replicates per treatment).

Differences in developmental time for control nymphs were tested by one-way analysis of variance (ANOVA). The mean survival time for the starved nymphs was analysed using two-way ANOVA with age and starvation condition as fixed factors. Statistical analyses were performed with SPSS 15.0 (SPSS, 2006). Prior to ANOVA,

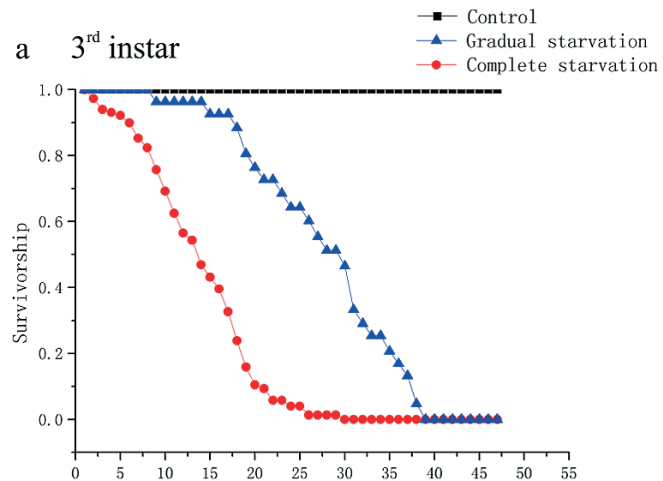

b $4^{\text {th }}$ instar

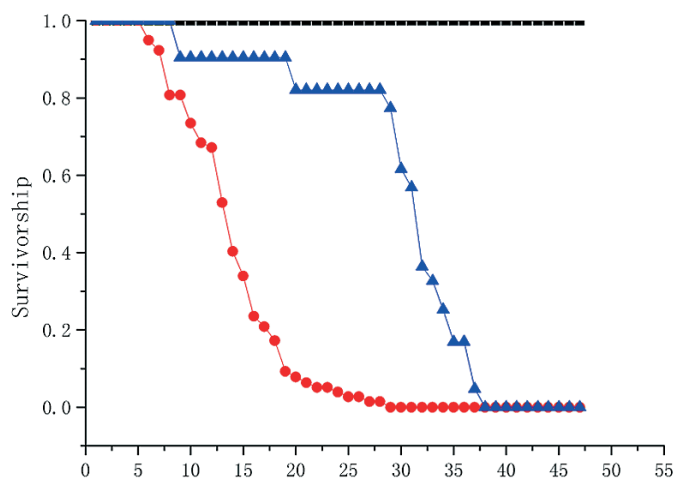

c $5^{\text {th }}$ instar

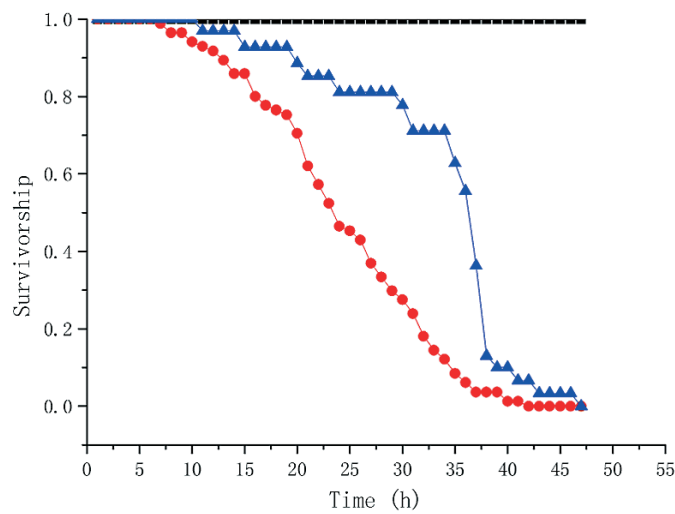

Fig. 1. Age-specific survivorship curves for three instars of Corythucha ciliata nymphs under complete, gradual or no starvation conditions. $-a .3^{\text {rd }}$ instar. $-b$. $4^{\text {th }}$ instar. - c. $5^{\text {th }}$ instar.

all data were checked for normality and equal variance. When treatment effects were significant $(P<0.05)$, the means were compared using Tukey's test. All survival percentages were arcsine-transformed prior to statistical analysis (Ju et al. 2011c, 2014). 
Table 1. Means \pm SE for survival time of the starved nymphs and developmental time of control nymphs (all survived in control) for Corythucha ciliata.

\begin{tabular}{lcccc}
\hline & \multicolumn{2}{c}{ Survival time $(\mathrm{h})$} & & Developmental time $(\mathrm{h})$ \\
\cline { 2 - 3 } & Complete starvation* $^{*}$ & Gradual starvation $^{*}$ & & Control $^{*}$ \\
\hline $3^{\text {rd }}$ instar & $13.0 \pm 1.34 \mathrm{~b}$ & $27.8 \pm 2.74 \mathrm{a}$ & & $52.0 \pm 5.32 \mathrm{~b}$ \\
$4^{\text {th }}$ instar & $15.9 \pm 0.68 \mathrm{~b}$ & $29.6 \pm 1.97 \mathrm{a}$ & & $61.5 \pm 6.47 \mathrm{~b}$ \\
$5^{\text {th }}$ instar & $24.4 \pm 1.74 \mathrm{a}$ & $33.6 \pm 1.81 \mathrm{a}$ & & $100.5 \pm 3.91 \mathrm{a}$ \\
$F_{2,6}$ & 17.5 & 1.8 & 23.1 \\
$\mathrm{P}$ & 0.003 & 0.24 & 0.002 \\
\hline
\end{tabular}

* Means within the same column followed by a different letter are significantly different (Tukey's test: $\mathrm{P}<0.05$ ).

\section{Results}

\subsection{Survival patterns under complete and gradual starvation conditions}

The shapes of the age-specific survivorship curves for the instars differed considerably under complete starvation and gradual starvation conditions (Fig. 1). Each instar exposed to complete starvation exhibited a type II age-specific survivorship curve (steady mortality throughout life). The nymphs exposed to gradual starvation initially exhibited type I curves (good initial survival but high death rates at later stages) but progressively exhibited type II curves. In the control, all nymphs of all three instars survived and developed to the next stage during the experiment.

\subsection{Survival time under complete and gradual starvation conditions}

No control nymphs died and their mean developmental time increased with the increase of age $\left(3^{\text {rd }}\right.$ instar: $52.0 \mathrm{~h} ; 4^{\text {th }}$ instar: $61.5 \mathrm{~h} ; 5^{\text {th }}$ instar: $100.5 \mathrm{~h}$ ). The mean developmental time of $5^{\text {th }}$ instar nymphs was significantly longer than that of $3^{\text {rd }}$ and $4^{\text {th }}$ instar nymphs, but there were no significant differences between $3^{\text {rd }}$ and $4^{\text {th }}$ instar nymphs (Table 1). As expected, both the starvation condition and the age of the nymphs had a significant effect on the mean survival time, but their interactions was not significant (Starvation condition: $F_{1,18}=67.3, P<0.001$; Age: $F_{2,18}=10.9, P$ $<0.001$; Starvation condition*Age: $F_{2,18}=1.1, P$ $=0.38)($ Table 1$)$.
Under complete starvation, $3^{\text {rd }}$ instar nymphs of $C$. ciliata had a mean survival time of $14.0 \mathrm{~h}$, whereas $4^{\text {th }}$ and $5^{\text {th }}$ instar nymphs of $C$. ciliata survived an average of $15.9 \mathrm{~h}$ and $24.4 \mathrm{~h}$, respectively. The average survival times of $3^{\text {rd }}$ and $4^{\text {th }}$ instar nymphs under complete starvation did not differ significantly but were both significantly shorter than that of $5^{\text {th }}$ instar nymphs. Under gradual starvation conditions, the average survival times of $3^{\text {rd }}$ to $5^{\text {th }}$ instar nymphs were $27.8 \mathrm{~h}, 29.6$ $\mathrm{h}$ and $33.6 \mathrm{~h}$, and there were no significant differences between instars (Table 1). The longestlived individual was a $5^{\text {th }}$ instar nymph subjected to gradual starvation, which died when it was 49 hours old.

\section{Discussion}

Many studies have reported that older instars survive longer under starvation conditions and are therefore more resistant to starvation stress than younger instars (Huang et al. 1985, Cao et al. 2010). For example, older instars of Epiblema strenuana (Walker) nymphs survive longer under starvation (Ma et al. 2002). Newly hatched larvae of Actinote anteas (Doubleday) and Actinote thaliapyrrha (Fabricius) survive under starvation for an average of $3 \mathrm{~d}$, whereas $2^{\text {nd }}$ and $4^{\text {th }}$ instar larvae survive for an average of $6 \mathrm{~d}$ and longer than $8 \mathrm{~d}$, respectively (Li et al. 2005). Similarly, in this study, $3^{\text {rd }}, 4^{\text {th }}$ and $5^{\text {th }}$ instar nymphs survived under complete starvation for an average of 14.0 $\mathrm{h}, 15.9 \mathrm{~h}$ and $24.4 \mathrm{~h}$, respectively. Similar survival was observed under gradual starvation, with average survival times of $27.8 \mathrm{~h}, 29.6 \mathrm{~h}$ and $33.6 \mathrm{~h}$, 
respectively (Table 1). These results thus further support the longer survival of older instars under starvation.

The age-specific survivorship curves generated under gradual starvation conditions considerably differed from those generated under complete starvation conditions for each instar stage. As there was no mortality in control, these two logically differed crucially also from the control. Under complete starvation conditions (no food supplied), the survival of $3^{\text {rd }}$ to $5^{\text {th }}$ instar nymphs tended to decline steadily (i.e., a type II survivorship curve). Under gradual starvation conditions (food provided once and not replenished), this process was delayed, and all nymphs exhibited type I curves (good initial survival but high death rates at later stages) in the initial stage (Fig. 1). This may be due to the similar conditions as the control at the initial stage (both were provided by food). These differences demonstrate that a certain amount of feeding may allowthem to store more energy, thus enhancing their starvation resistance (Rion \& Kawichi 2007).

Corythucha ciliata can spread very quickly. For example, in Italy, the distribution of the sycamore lace bug was confined to areas surrounding the Venice port in 1960. By 1974, they had spread to the northern and central regions of Italy (Venturi 1974). By 2000, they were distributed throughout the whole country, including two islands, Sardinia and Sicily (Mazzon et al. 2000). Similarly, C. ciliata spread over $80,000 \mathrm{~km}^{2}$ in 10 years in Hungary, and 25 cities were populated by the insect by 2000 (Kozar \& Nagyne 1985, Kukedi 2000). Corythucha ciliata may have spread from North America to Italy via transport on oceanic vessels (Özsi et al. 2005). In addition, other vehicles (trucks, buses) may also carry $C$. ciliata adults or nymphs to other trees when they come into contact with infested branches and leaves, causing the spread of the bug (Arzone 1975). Human transportation of plants and logs with bark attached were ultimately identified as the main cause of long-distance spread (Ju et al. 2009).

The ability of an exotic insect species to overcome stressful starvation conditions during transport is a prerequisite for successful colonisation. In this study, we demonstrated that $3^{\text {rd }}$ to $5^{\text {th }}$ instar nymphs of $C$. ciliata can survive without food for at least $13 \mathrm{~h}$ at an average temperature of $26^{\circ} \mathrm{C}$ and a relative humidity of $80 \%$. If the nymphs were transported with their host tree (even one leaf), they would survive for longer periods, at least $27 \mathrm{~h}$. The survival time of this species is likely to be longer at lower temperatures (Ji et al. 2010). Assuming that the average speed of a vehicle is only $60 \mathrm{~km} / \mathrm{h}, 3^{\text {rd }}$ to $5^{\text {th }}$ instar nymphs of $C$. ciliata may arrive at a new location $780 \mathrm{~km}$ away. This survival capacity explains why $C$. ciliata has undergone such rapid global spread.

Phytosanitary measures are very common for preventing the diffusion of alien species to pestfree areas (Hallman 2007). The longest-lived individual nymph in the test groups in this study did not die until 49 hours after exposure to starvation at a constant temperature of $26^{\circ} \mathrm{C}$ (a developmental reference temperature, see Ju et al. 2011b, c, 2013). Although the starvation-resistant capacity of this species under different temperature conditions requires further study, quarantine regulations should be strengthened to prevent $C$. ciliata diffusion into pest-free areas.

Acknowledgements. The authors thank two anonymous reviewers for their helpful comments and suggestions to improve the paper. We thank the native English speaking scientists of American Journal Experts Company for improving the English language in this manuscript. This research was financially supported by grants from the National Natural Science Foundation of China [grant number 31440033] and the Projects of Shandong Science and Technology Plans [grant number 2013GGB22002].

\section{References}

Arzone, A. 1975: The plane lace-bug in Piedmont: biological cycle and dispersal. - Montie Boschi 26(3): 1927. [In Italian.]

Bauerfeind, S. S., Fischer, K. \& Larsson, S. 2005. Effects of food stress and density in different life stages on reproduction in a butterfly. - Oikos 111(3): 514-524.

Berrigan, D. \& Charnov, E. L. 1994: Reaction norms for age and size at maturity in response to temperature: a puzzle for life historians. - Oikos 70: 474-478.

Blanckenhorn, W. U. 1998: Adaptive phenotypic plasticity in growth, development, and body size in the yellow dung fly. - Evolution 52: 1394-1407.

Boggs, C. L. \& Freeman, K. D. 2005: Larval food limitation in butterflies: effects on adult resource allocation and fitness. - Oecologia 144(3): 353-361.

Boggs, C. L. \& Ross, C. L. 1993: The effect of adult food limitation on life history traits in Speyeria mormonia 
(Lepidoptera: Nymphalidae). — Ecology 74: 433441.

Braby, M. F. \& Jones, R. E. 1995: Reproductive patterns and resource allocation in tropical butterflies: influence of adult diet and seasonal phenotype on fecundity, longevity and egg size. - Oikos 72: 189-204.

Cao, C. Q., Chen, S. Z., Lin, Z. Y., Huang, C. J., Liang, H. Y. \& Li, Y. D. 2010: Influence of starvation on the growth and feeding of Locusta migratoria manilensis. - Chinese Bulletin of Entomology 47(3): 517-519. [In Chinese.]

Chen, C. H. \& Gu, S. H. 2006: Stage-dependent effects of starvation on the growth, metamorphosis, and ecdysteroidogenesis by the prothoracic glands during the last larval instar of the silkworm, Bombyx mori. Journal of Insect Physiology 52(9): 968-974.

Chung, Y. L., Kwon, T. S., Yeo, W. H., Byun, B. K. \& Park, C. H. 1996: Occurrence of the sycamore lace bug, $\mathrm{Co}$ rythucha ciliata (Say) (Hemiptera: Tingidae) in Korea. - Korean Journal of Applied Entomology 35(2): 137-139.

d'Aguilar, J., Pralavorio, R., Rabasse, J. M. \& Mouton, R. 1977: Introduction en France du tigre du platane: $\mathrm{Co}$ rythucha ciliata (Say) (Het. Tingidae). - Bulletin de la Société Entomologique de France 82: 2-6. [In French.]

Daglish, G. J. 2006: Survival and reproduction of Tribolium castaneum (Herbst), Rhyzopertha dominica (F.) and Sitophilus oryzae (L.) following periods of starvation. - Journal of Stored Products Research 42(3):328-338.

Dominiak, B. C., Gillespie, P. S., Worsley, P. \& Löcker, H. 2008: Survey for sycamore lace bug Corythucha ciliata (Say) (Hemiptera: Tingidae) in New South Wales during2007. - General and Applied Entomology $37: 27-30$.

Froeschner, R. C. 1988: Family Tingidae Laporte, 1807: 708-733. - In: Henry, T. J. \& Froeschner, R. C. (eds.), Catalog of the Heteroptera, or True Bugs, of Canada and the Continental United States. E. J. Brill, Leiden.958 pp.

Halbert, S. E. \& Meeker, J. R. 1998: The sycamore lace bug, Corythucha ciliata (Say) (Hemiptera: Tingidae). - Entomology Circular (Gainesville). 2 pp.

Hallman G. J. 2007: Phytosanitary measures to prevent the introduction of invasive species: 367-384. - In: Nentwig, W. (ed.), Biological invasions. Springer, Berlin, Heidelberg. 434 pp.

Hoffmann H. J. 2003: The Sycamore lace bug Corythucha ciliata (Say, 1872) arrives at the Lower Rhine (Heteroptera). - Entomologische Nachrichten und Berichte 47(2): 67-70. [In German.]

Huang, C. W., Feng, B. C., Wang, H. D., Yao, J. \& Song, L. J. 1985: Host and starvation tolerance of Sogatella furcifera Horváth. - Chinese Bulletin of Entomology 22(5): 193-194. [In Chinese.]

Ji, H. L., Tang, L. D. \& Wu, X. Y. 2013: Occurrence and control of Corythucha ciliata in Kunshan. - Ningxia Journal of Agriculture and Forestry Science \& Technology 54(5): 74-75. [In Chinese.]
Ji, R., Xiao, Y. T., Luo, F., Yuan, H. L., Zhou, G. X., Fan, L. J. \& Lou, Y. G. 2010: Efficacy tests of nine kinds of pesticides for controlling Corythucha ciliata. - Chinese Bulletin of Entomology 47(3): 543-546. [In Chinese.]

Jiang, Y. C. \& Lin, S. J. 1965: Effects of starvation resistance and hunger on fecundity of Cinara pinea Mordvilko. - Chinese Bulletin of Entomology 9(1):52-53. [In Chinese.]

Johnson, T. E., de Castro, E., de Castro, S. H., Cypser, J., Henderson, S., \& Tedesco, P. 2001: Relationship between increased longevity and stress resistance as assessed through gerontogene mutationsin Caenorhabditis elegans. - Experimental Gerontology 36(10):1609-1617.

Ju, R. T., Gao L., Zhou X. H. \& Li, B. 2013: Tolerance to high-temperature extremes in an invasive lace bug, Corythucha ciliata (Hemiptera: Tingidae), in subtropical China. — PLoS ONE 8:e54372

Ju, R. T., Gao, L., Zhou, X. H. \& Li, B. 2014: Physiological responses of Corythucha ciliata adults to high temperatures under laboratory and field conditions. — Journal of Thermal Biology 45: 15-21.

Ju, R. T., Li, Y. Z., Wang, F. \& Du, Y. Z. 2009: Spread of an exotic species, Corythucha ciliata (Say, 1832), in China (Hemiptera: Tingidae). — Entomology News 120: 409-414.

Ju, R. T., Wang, F. \& Li, B. 2011a: Effects of temperature on the development and population growth of the sycamore lace bug, Corythucha ciliata. - Journal of Insect Science 11:16.

Ju, R. T., Xiao, Y. Y.\& Li, B. 2011b: Rapid cold hardening increases cold and chilling tolerances more than acclimation in the adults of the sycamore lace bug, Corythucha ciliata (Say) (Hemiptera: Tingidae). — Journal of Insect Physiology 57(11): 1577-1582.

Ju, R. T., Chen, G. B., Wang, F. \& Li, B. 2011c: Effects of heat shock, heat exposure pattern, and heat hardening on survival of the sycamore lace bug, Corythucha ciliata (Say) (Hemiptera: Tingidae). — Entomologia Experimentalis et Applicata 141(2): 168-177.

Ju, Z., Zhao, J. N., Ding, F. B., Qu, J. J., Li, M. G. \& Xu, Y. Y. 2008: Effects of starvation on the development and reproduction of Hyphantria cunea. - Chinese Bulletin of Entomology 45(3):437-440. [In Chinese.]

Karl, I., Lorenz, M. W. \& Fischer, K. 2007: Energetics of reproduction: consequences of divergent selection on egg size, food limitation, and female age for egg composition and reproductive effort in a butterfly. - Biological Journal of the Linnean Society 91(3): 403-418.

Kehl, T. \& Fischer, K. 2012: Larval starvation reduces responsiveness to feeding stimuli and does not affect feeding preferences in a butterfly. - Journal of Insect Physiology 58(7): 1028-1035.

Kim, J. K. \& Jeong, J. 1999. Ecological studies on the sycamore lace bug, Corythucha ciliata (Hemiptera: Tingidae). I. Developmental characteristics, adult behavior and sex ratio. - Journal of Research Forests of Kangwon National University 19: 1-5. [In Korean.]

Kozar, F. \& Nagyne, D. A. 1985: Unexpected northward 
spreading of some insect species in Central Europe, and climatic changes. - Novenyvedelem 21(5): 214. [In Hungarian.]

Kukedi, E. 2000: On Corythucha ciliata Say (Heteroptera, Tingidae) and its spread. - Novenyvedelem 36(6): 313-317. [In Hungarian.]

Lavy, D., Nedved, O. \& Verhoef, H. A. 1997: Effects of starvation on body composition and cold tolerance in the collembolan Orchesella cincta and the isopod Porcellio scaber. - Journal of Insect Physiology 43(10): 973-978.

Li, C. R., Xia, W. S. \& Wang, F. L. 2007: First records of Corythucha ciliata (Say) in China (Hemiptera, Tingidae). - Acta Zootaxonomica Sinica 32(4): 944-946. [In Chinese.]

Li, Z. G., Han, S. C., Guo, M., Li, L. Y., Peng, T. X., Liu, W. H. \& Luo, L. F. 2005: Starvation endurance ability of Actinote anteas and Actinote thalia pyrrha larvae. — Chinese Bulletin of Entomology 42(4): 429 -430. [In Chinese.]

Lin, C. C., Lu, G., Zhou, C. M. \& Zhao, J. N. 2003: Impacts of adult feeding materials on the life span of Monochamus alternatus. — Forest Research 16(1): 69-74. [In Chinese.]

Liu, M., Chen, L. C. \& Yan, Y. 2012: Occurrence and damage of Corythucha ciliata in Hunan Province. Hunan Forestry Science \& Technology 39(1): 99-100. [In Chinese.]

Ma, J., Wan, F. H., Guo, J. Y., You, L. S. \& Lu, D. Y. 2002: Risk Analysis of Host Specificity for Epiblema strenuana (Lepidoptera: Tortricidae), a Biocontrol Agent Against Ragweed, Ambrosia artemisiifolia (Compositae). - Acta Ecologica Sinica 22(10): 1710-1717. [In Chinese.]

Mazzon, L. \& Girolami, V. 2000: The sycamore lace bug. — Sherwood-Foreste ed Alberi Oggi 6(6): 27-28. [In Italian]

Özsi, B. L., Landanyi, M. \& Hufnagel, L. 2005: Population dynamics of the Sycamore lace bug, Corythucha ciliata (Hemiptera: Tingidae) in Hungary. - Applied Ecology and Environmental Research 4(1):135-150.

Pijpe, J., Brakefield, P. M. \& Zwaan, B. J. 2008. Increased life span in a polyphenic butterfly artificially selected for starvation resistance. - The American Naturalist 171(1): 81-90.

Prado, C. E. 1990: Presenciaen Chile de Corythucha ciliata (Say) (Hemiptera: Heteroptera: Tingidae). — Revista Chilenade Entomologia 18: 53-55. [In Spanish.]

Rabitsch W. 2008. Alien true bugs of Europe (Insecta: Hemiptera: Heteroptera). — Zootaxa 1827: 1-44.
Rion S. \& Kawichi T. J. 2007: Evolutionary biology of starvation resistance: what we have learned from Drosophila. - Journal of Evolutionary Biology 20(5): 1644-1655.

Robinson, S. J. W., Zwaan, B. \& Partridge, L. 2000: Starvation resistance and adult body composition in a latitudinal cline of Drosophila melanogaster. - Evolution 54(5): 1819-1824.

Sheng, J., Lin, Q., Chen, Q., Shen, L. \& Lu, J. 2007: Effect of starvation on the initiation of feeding, growth and survival rate of juvenile seahorses, Hippocampus trimaculatus Leach and Hippocampus kuda Bleeker. Aquaculture 271(1): 469-478.

SPSS. 2006: SPSS Base 15.0 User's Guide. - SPSS, Chicago, IL, USA. 736 pp.

Stockhoff, B. nA. 1991: Starvation resistance of Gypsy Moth, Lymantria dispar (L.) (Lepidoptera: Lymantriidae): Tradeoffs among growth, body size, and survival. - Oecologia 88(3): 422-429.

Tokihiro, G., Tanaka, K. \&Kondo, K. 2003.Occurrence of the sycamore lace bug, Corythucha ciliata (Say) (Heteroptera: Tingidae) in Japan. - Research Bulletin of the Plant Protection Service 39: 85-87. [In Japanese.]

Venturi, F. 1974: A new threat to our plane trees: the American lace bug Corythucha ciliata (Say). — Frustula Entomologica 12(1): 9. [In Italian.]

Vermeulen, C. J., Zande, L. V. D. \& Bijlsma, R. 2006: Developmental and age-specific effects of selection on divergent virgin life span on fat content and starvation resistance in Drosophila melanogaster. - Journal of Insect Physiology 52(9): 910-919.

Wu, H. W., Li, D. J., Wang, X. N., Wang, L. D., Li, X. C. \& Liu, H. X. 2013: Debelopment situation and control measures for Corythucha ciliata in Shandong. Journal of Shandong Forestry Science and Technology 4: 108-110. [In Chinese.]

Xiao, Y. Y., Wang, F., Ju, R. T., Li, Y. Z. \& Du, Y. Z. 2010: Life history and occurrence of Corythucha ciliata in Shanghai. - Chinese Bulletin of Entomology 47(2): 404-408. [In Chinese.]

Zhang, J., Huang, J., Hou, J. X., Xu, D. L. \& Shi, Z. H. 2012: Heat and starvation induced hormesis in longevity of Oomyzus sokolowskii (Kurdjumov) (Hymenoptera: Eulophidae) adult females. - Journal of Thermal Biology 37(8): 696-701.

Zheng, T., Cui, X. H., Wang, T., Xu, X. H., Xu, D. C. \& Shang, H. W. 2011: Effects of starvation on survival rate and oviposition of the invasive mealybug Phenacoccus solenopsis (Hemiptera: Pseudococcidae). Journal of Biosafety 20(3): 239-242. [In Chinese.] 